\title{
Conventional vestibular function tests vs. butterfly vestibulometry in peripheral vertigo
}

\author{
Sharma $V^{1 *}$ Shah $R^{1}$ \\ ${ }^{1}$ Dept. of Otorhinolaryngology, Manipal College of Medical Sciences \& \\ Teaching Hospital, Phulbari Campus, Pokhara, Nepal
}

\author{
*Corresponding Author: \\ Dr. Vishal Sharma \\ Associate Professor, \\ Dept. of Otorhinolaryngology, \\ Manipal College of Medical Sciences \& Teaching Hospital \\ Phulbari Campus, Pokhara, Nepal. \\ E-mail address: vishal_sharma_ent@yahoo.com

\section{Citation} \\ Sharma V, Shah RK. Conventional vestibular function \\ tests vs. butterfly vestibulometry in peripheral vertigo. \\ Nepal Journal of Medical sciences 2014;3(1):31-37.
}

\begin{abstract}
Background: To perform conventional vestibular function tests \& butterfly vestibulometry via electronystagmography (E.N.G.) in patients diagnosed clinically as suffering from peripheral vertigo. To rule out the presence of a central lesion in clinically diagnosed patients of peripheral vertigo.
\end{abstract}

Methods: This is a prospective, cross-sectional, case series study conducted in 50 normal subjects and 138 patients clinically diagnosed as suffering from peripheral vertigo (excluding benign paroxysmal positional vertigo), who were subjected to conventional vestibular function tests \& butterfly vestibulometry.

Results: Conventional bithermal caloric test identified a nystagmus in $13.04 \%$ patients while E.N.G. assisted bithermal caloric test identified a nystagmus in $91.30 \%$ patients. Thus in our study the sensitivity of identifying a nystagmus increased 7 times when comparing conventional bithermal caloric test to E.N.G. assisted caloric test. During E.N.G., among the pathological group $8.96 \%$ had normal response, $80.43 \%$ had a peripheral lesion, $7.97 \%$ had a central lesion and $2.89 \%$ had a non-localizing lesion. Among the control group 96\% had normal response and 4\% had a peripheral lesion. Among the 11 central causes of vertigo diagnosed by E.N.G., 4 cases were also diagnosed by M.R.I. of brain but in 7 cases $(63.63 \%)$ no structural pathology was seen.

Conclusion: E.N.G. has 7 times more sensitivity to elicit nystagmus when compared to Fitzgerald Hallpike bithermal caloric test. E.N.G. can pick up central causes for vertigo amongst cases clinically diagnosed as peripheral vertigo. It has a better sensitivity to diagnose a central cause for vertigo when compared to M.R.I. of brain.

Keywords: Butterfly vestibulometry; electronystagmography; peripheral vertigo

\section{Background:}

Electronystagmography (E.N.G.) recording is made by utilizing the corneo-retinal potential difference described by Emil Du Bois-Reymond, 1849. ${ }^{1}$ It helps in recording nystagmus even behind closed eyes or with eyes open in darkness. Butterfly vestibulometry is a method of presenting E.N.G. findings to diagnose vestibular lesions. The E.N.G. parameter used in this method is the culmination frequency of the caloric nystagmus. The advantage of the butterfly vestibulometry is that a diagnosis can be made simply by observing the visual presentation of the butterfly chart. 


\section{Methods:}

A total of 562 patients presented to the O.P.D. in the department of Otorhinolaryngology, Manipal Teaching Hospital, Pokhara between 1st April 2011 and 31st March 2013, with dizziness as their chief complaint. From history taking itself 240 patients were found to have vertigo like non-rotatory symptoms and were excluded from this study. The remaining 322 patients of true vertigo were subjected to routine vestibular function tests like spontaneous nystagmus, gaze-evoked nystagmus, head shake test, fistula test, positional tests, Dix-Hallpike test, Fitzgerald Hallpike bithermal caloric test, Romberg test and tests for cerebellar function. After the tests we used the following criteria on these 322 patients to choose patients having peripheral vertigo and exclude patients having central vertigo.

\section{Clinical criteria for peripheral vertigo:}

1. Positional vertigo confirmed by positive Dix Hallpike test 2. Abrupt onset vertigo. 3. Vertigo associated with unilateral deafness, tinnitus and aural fullness. 4. Vertigo associated with severe nausea and vomiting. 5. Character of nystagmus (presence of latency of 2-10 seconds, duration less than 1 minute, fatigability or disappearance on repetition of test condition, direction of nystagmus is fixed).

\section{Clinical criteria for central vertigo:}

1. Gradual onset vertigo. 2. Associated with hypertension, atrial fibrillation, cerebrovascular accident, advanced age. 3 . Character of nystagmus (absence of latency, duration more than 1 minute, absence of fatigability, direction of nystagmus keeps changing). 4. Presence of neurological signs (positive Babinski sign, cerebellar ataxia, focal neurological deficits)

174 of the 322 patients of true vertigo had classical symptoms of benign paroxysmal positional vertigo (BPPV), so their diagnosis was confirmed by Dix Hallpike maneuver and they were excluded from this study. 10 of these 322 patients of true vertigo had clinical signs of central lesion and were also excluded from this study. The remaining 138 patients with a clinical diagnosis of non-BPPV peripheral vertigo were included in this study and subjected to butterfly vestibulometry via electronystagmography.

Research design: Prospective, cross-sectional case series study.

The study was conducted in 50 normal subjects (normal group) and 138 patients clinically diagnosed as suffering from non-BPPV peripheral vertigo (pathological group). The two groups were compared in terms of non- caloric test findings, caloric test findings and electronystagmography findings. The statistical analysis was done by Fisher's exact test. A $p$ value of $<0.05$ was considered significant.

The following were the inclusion and exclusion criteria of the pathological group-

\section{Inclusion criteria:}

1. Patient above the age of 18 years who presented with dizziness.

2. Patient who gave written informed consent for electronystagmography.

\section{Exclusion criteria:}

1. Age less than 18 years as they may not cooperate during electronystagmography. 2. Presence of ear wax. 3. Discharge from the ear. 4. Infection in the ear. 5. Perforation in the tympanic membrane. 6. Patient under the influence of alcohol, certain drugs (sedatives, hypnotics, antihistamines and other anti-vertigo medication) for past 72 hours. 7 . Operated mastoid cavity

\section{Procedure of Electronystagmography:}

Saccade test was done by asking the patient to look back and forth between 2 red LED dots separated by a distance of 20 degrees.

Tracking test was done by asking the patient to look at a red LED dot moving back and forth in a sinusoidal waveform.

Spontaneous nystagmus test was done next. Patient was put in caloric test position first with eyes open in light for 1 minute and then with eyes closed in a dark room to remove optic fixation for 1 minute. Minimum slow component velocity required to qualify as nystagmus was fixed at 4 degree per second.

Gaze nystagmus test was done by asking the patient to follow the red LED dot first kept centrally $30 \mathrm{~cm}$ from patient's eyes \& moved in horizontal \& vertical planes within 30 degrees only.

Optokinetic test was done by asking the patient to follow a rapidly moving red LED dot (coming from lateral end to midline by 20 degrees and going back and forth) or by looking at a series of moving black and white stripes on a rotating drum.

Positional test was done next by moving the patient slowly in 11 different positions maintained for 30 seconds each. 5 sitting positions were head upright, right side down, left side down, head extended \& head flexed. 6 supine positions were head straight, right side down, left side down, head hanging 
straight, head hanging with right turn \& head hanging with left turn.

Bithermal Caloric test was done at last. Positioning of the patient has already been done. The temperatures of water selected for the caloric test were $44^{\circ}$ and $30^{\circ}$ centigrade for both right and left ears. The quantity of water used for caloric test is $20 \mathrm{cc}$ taken in a $20 \mathrm{ml}$ syringe. Returning water was collected in a kidney tray. Irrigation was done in the order $44^{0}$ left, $44^{0}$ right, $30^{\circ}$ left, $30^{\circ}$ right i.e. from the weakest to the strongest stimuli. The interval of at least 5 minutes was maintained between two successive irrigations. Recording was started immediately at the start of the irrigation and was continued for two and half minutes to three minutes. Alertness of the patient was maintained throughout the test by giving him/her to solve simple arithmetical problems depending on his/her educational status.

In our study, we calculated the culmination frequency as the parameter for the purpose of diagnosis. It is a sensitive parameter as a maximum velocity of slow component of nystagmus. The other purpose for selection of this parameter is due to the fact that its estimation was simple and accurate and personnel error is negligible. The entire tracing was divided in 10 seconds intervals. The number of beats in each 10 seconds is counted. The three adjacent ten seconds intervals showing together the highest number of beats constitute the culmination phase. The total number of beats in this culmination phase is called culmination frequency. The normal ranges for culmination frequencies as found from our normal group patients were: a. Right warm $=22$ - 59 beats / 30 seconds. b. Right cold $=24-67$ beats $/ 30$ seconds. c. Left warm $=23-63$ beats $/ 30$ seconds. d. Left cold $=27-68$ beats $/ 30$ seconds.

Graphical presentation of this data was given as Butterfly chart (Figure 1). The chart consists of 4 quadrants, each represents one caloric reaction. The abscissa or the horizontal axis represents 30 seconds of time in the culmination phase $(1 \mathrm{~mm}=1 \mathrm{sec})$. The ordinate or the vertical axis represent the number of the nystagmus beats or culmination frequency $(1 \mathrm{~mm}=1$ beat $)$.

The normal range of the caloric response is superimposed on the vertical axis of the quadrant. Response within this range is considered as normal, those below it as hypoactive and those above it as hyperactive. Butterfly Chart consists of 4 such quadrants for the four caloric reactions, each with it corresponding normal range. For the convenience, the response is designated by digits as follows: Normal $=0$, Hypoactive $=1$ and Hyperactive $=2$. Result was given as code of 4 digits in order of: Right warm, Right cold, Left warm, Left cold. The limit of normality for spontaneous nystagmus, in either direction is represented by horizontal dotted lines. Spontaneous nystagmus to the right is represented in both the quadrants above the horizontal axis, while spontaneous nystagmus to the left is represented in both the quadrants below it. This is because one does not always know which ear is responsible for generating the spontaneous nystagmus.

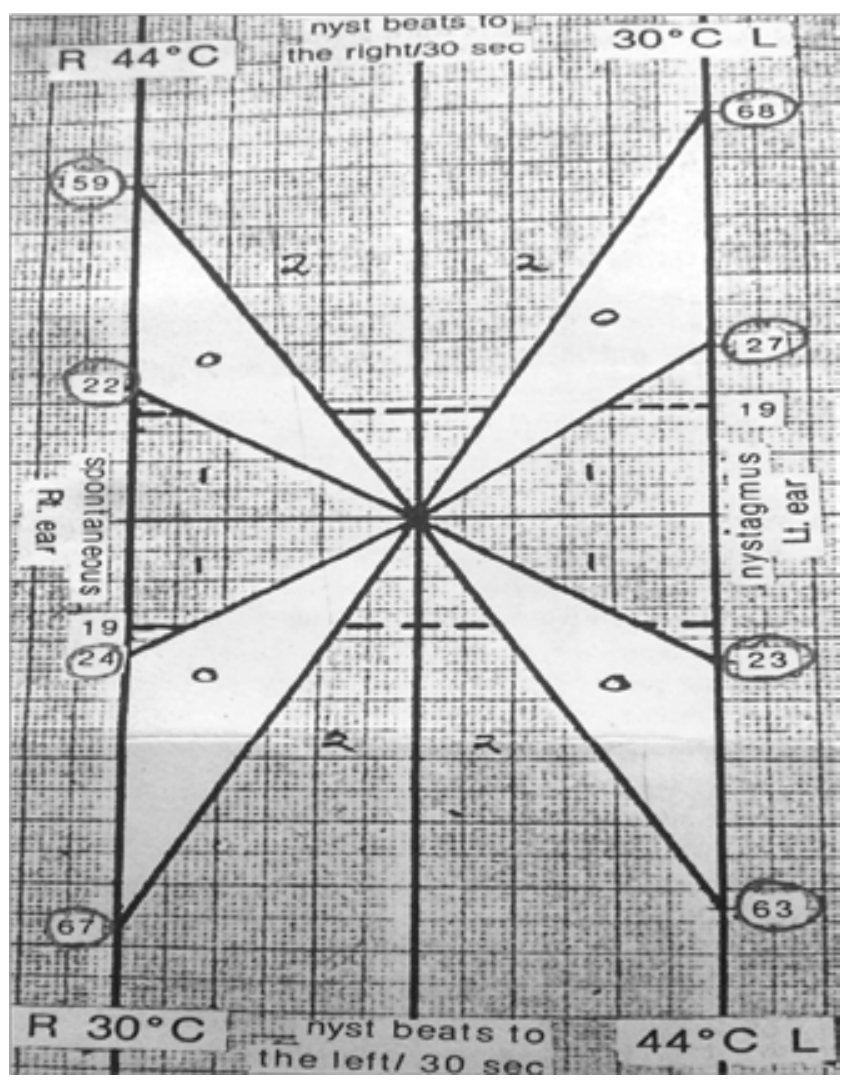

Figure 1: Butterfly chart

\section{Indicators of central pathology (brainstem or cerebellum) in E.N.G. are:}

1. Failure of suppression of nystagmus by optic fixation and abolished or diminished by eye closure. 2. Vertical nystagmus. 3. Direction changing nystagmus. 4. Saccadic hypermetria. 5. Bilateral gaze paretic nystagmus i.e. right beating nystagmus on the right gaze and left beating nystagmus on the left side. 6. Nystagmus not enhanced by gazing in the direction of fast phase. 7. Tracking test shows breakup of the smooth pursuit tracing. 8. Asymmetric responses in optokinetic test. 9. Positional test nystagmus abnormality suggesting central pathology (immediate onset with no latency, ageotropic, direction changing, nonfatigable). 10. Abnormal butterfly chart codes of central pathology (2200, 0022, 0110, and 1001). 
Indicators of peripheral pathology (labyrinth or vestibular nerve) in E.N.G. are:

1. Nystagmus suppressed by optic fixation and enhanced by eye closure. 2. Horizontal or horizontal rotatory nystagmus. 3. Nystagmus with fixed direction. 4. No evidence of saccadic hypermetria. 5. Nystagmus enhanced by gazing in the direction of fast phase. 6. No evidence of bilateral gaze paretic nystagmus. 7. No evidence of breakup of the smooth pursuit tracing. 8. No evidence of asymmetric responses in optokinetic test.

9. Positional test nystagmus abnormality suggesting peripheral pathology (presence of latency before onset, geotropic, direction fixed, fatigable). 10. Abnormal butterfly chart codes of peripheral pathology (1100, 0011, 1010, and 0101).

\section{Results:}

The youngest patient in our study was 21 years old while the oldest patient was 78 years old. The average age was 44.02 years (S.D. +13.51) for pathological group cases and 32 years (S.D. \pm . 14.09) for normal group cases. Among the patients in pathological group, 55.79\% were males and $44.21 \%$ females. Among the patients in normal group, $64 \%$ were males and $36 \%$ females. The minimum duration of vertigo seen in our pathological study group was 15 days ( 0.5 months) while the maximum duration was 48 months. The average duration was 7 months (S.D. $+10.39)$.

During non-caloric tests of routine vestibular function evaluation, 5 (3.62\%) patients of pathological group had a positive fistula test while 10 (7.24\%) showed sensory ataxia on Romberg test with ipsilateral swaying of body only with eyes closed. All test findings in normal group were negative. Among the patients in pathological group $120(86.95 \%)$ had normal response and 18 (13.04\%) had canal paresis in Fitzgerald Hallpike bithermal caloric test. Among the control group 50 (100\%) had normal responses in bithermal caloric test.

During the non-caloric tests in E.N.G., 111 patients (80.4\%) among the pathological group had their nystagmus enhanced by eye closure which is indicative of a peripheral lesion, 11 patients $(7.97 \%)$ had one or more of the criteria for a central lesion present and 7 patients (5.07\%) had spontaneous nystagmus of no localizing value. Among the control group 48 (96\%) had normal response and 2 (4\%) had spontaneous nystagmus of no localizing value. (Table 1)
Table 1: Non-caloric test findings in E.N.G.

\begin{tabular}{|c|c|c|c|c|}
\hline \multirow[t]{2}{*}{ Category } & \multicolumn{2}{|c|}{$\begin{array}{l}\text { Pathological } \\
\text { group }\end{array}$} & \multicolumn{2}{|c|}{$\begin{array}{l}\text { Normal } \\
\text { group }\end{array}$} \\
\hline & Number & $(\%)$ & Number & $(\%)$ \\
\hline Spontaneous nystagmus & 7 & 5.07 & 2 & 4 \\
\hline Bilateral gaze paretic nystagmus & 6 & 4.34 & 0 & 0 \\
\hline Saccade hypermetria & 3 & 2.17 & 0 & 0 \\
\hline $\begin{array}{l}\text { Smooth pursuit nystagmus } \\
\text { abnormality }\end{array}$ & 2 & 1.45 & 0 & 0 \\
\hline $\begin{array}{l}\text { Asymmetric optokinetic } \\
\text { nystagmus }\end{array}$ & 3 & 2.17 & 0 & 0 \\
\hline $\begin{array}{l}\text { Positional nystagmus } \\
\text { abnormality }\end{array}$ & 8 & 5.79 & 0 & 0 \\
\hline Vertical nystagmus & 3 & 2.17 & 0 & 0 \\
\hline Direction changing nystagmus & 8 & 5.79 & 0 & 0 \\
\hline $\begin{array}{l}\text { Nystagmus enhanced by eye } \\
\text { closure }\end{array}$ & 111 & 80.4 & 0 & 0 \\
\hline $\begin{array}{l}\text { Nystagmus diminished by eye } \\
\text { closure }\end{array}$ & 11 & 8 & 0 & 0 \\
\hline $\begin{array}{l}\text { Nystagmus not affected by eye } \\
\text { closure }\end{array}$ & 16 & 11.6 & 0 & 0 \\
\hline
\end{tabular}

Table 2 shows the different butterfly chart codes seen in bithermal caloric test for pathological group.

Table 2: Butterfly chart codes seen in caloric test for pathological group

\begin{tabular}{|c|c|c|c|}
\hline $\begin{array}{l}\text { Butterfly } \\
\text { code }\end{array}$ & $\begin{array}{c}\text { No. of } \\
\text { patients }\end{array}$ & Interpretation & Inference \\
\hline \multicolumn{4}{|c|}{ Normal (12) } \\
\hline 0000 & 12 & Normal response & Normal balance function \\
\hline \multicolumn{4}{|c|}{ Peripheral lesion (111) } \\
\hline 1100 & 41 & Right canal paresis & Right vestibular lesion \\
\hline 0011 & 39 & Left canal paresis & Left vestibular lesion \\
\hline 1010 & 26 & $\begin{array}{l}\mathrm{B} / \mathrm{L} \text { decreased warm } \\
\text { response }\end{array}$ & $\mathrm{B} / \mathrm{L}$ vestibular lesions \\
\hline 0101 & 5 & $\begin{array}{l}\mathrm{B} / \mathrm{L} \text { decreased cold } \\
\text { response }\end{array}$ & $\mathrm{B} / \mathrm{L}$ vestibular lesions \\
\hline \multicolumn{4}{|c|}{ Central lesion (11) } \\
\hline 2200 & 5 & $\begin{array}{l}\text { Right nystagmus } \\
\text { dysinhibition }\end{array}$ & Left cerebellar lesion \\
\hline 0022 & 2 & $\begin{array}{l}\text { Left nystagmus } \\
\text { dysinhibition }\end{array}$ & Right cerebellar lesion \\
\hline 0110 & 3 & $\begin{array}{l}\text { Left directional } \\
\text { inhibition }\end{array}$ & Left brainstem lesion \\
\hline 1001 & 1 & $\begin{array}{l}\text { Right directional } \\
\text { inhibition }\end{array}$ & Right brainstem lesion \\
\hline \multicolumn{4}{|c|}{ Non-localizing lesion (4) } \\
\hline 2002 & 3 & $\begin{array}{l}\text { Right directional } \\
\text { preponderance }\end{array}$ & Pathology not localized \\
\hline 0220 & 1 & $\begin{array}{l}\text { Left directional } \\
\text { preponderance }\end{array}$ & Pathology not localized \\
\hline
\end{tabular}


Among the pathological group 12 patients (8.96\%) had normal response, $111(80.43 \%)$ had peripheral lesion, 11 (7.97\%) had central lesion and 4 (2.89\%) had non localizing lesion. In the control group 48 subjects $(96 \%)$ had normal response and $2(4 \%)$ had a peripheral lesion. The $\mathrm{p}$ values for diagnosing normal response, peripheral lesion and central lesion were stastically significant (Table 3 ).

Table 3: Butterfly chart disease localization in caloric test of E.N.G.

\begin{tabular}{|c|c|c|c|c|c|}
\hline \multirow[t]{2}{*}{ Category } & \multicolumn{2}{|c|}{$\begin{array}{c}\text { Pathological } \\
\text { group }\end{array}$} & \multicolumn{2}{|c|}{ Normal group } & \multirow{2}{*}{$\begin{array}{c}P \\
\text { value }\end{array}$} \\
\hline & Number & $(\%)$ & Number & $(\%)$ & \\
\hline $\begin{array}{l}\text { Normal } \\
\text { response }\end{array}$ & 12 & 8.69 & 48 & 96 & 0.0001 \\
\hline $\begin{array}{l}\text { Peripheral } \\
\text { lesion }\end{array}$ & 111 & 80.43 & 02 & 4 & 0.0001 \\
\hline Central lesion & 11 & 7.97 & 0 & 0 & 0.0387 \\
\hline $\begin{array}{l}\text { Non-localizing } \\
\text { lesion }\end{array}$ & 04 & 2.89 & 0 & 0 & 0.575 \\
\hline
\end{tabular}

Conventional Fitzgerald Hallpike bithermal caloric test identified a nystagmus in 18 out of 138 (13.04\%) patients while E.N.G. assisted bithermal caloric test identified a nystagmus in 126 out of $138(91.30 \%)$ patients. Thus sensitivity of identifying a nystagmus increased 7 times with the help of E.N.G. This finding was extremely statistically significant (Table 4).

Table 4: Diagnostic sensitivity for nystagmus identification

\begin{tabular}{lcc}
\hline Disease & $\begin{array}{c}\text { ENG caloric } \\
\text { test }\end{array}$ & $\begin{array}{c}\text { Conventional } \\
\text { caloric test }\end{array}$ \\
\hline Nystagmus detected & 126 & 12 \\
Nystagmus not detected & 18 & 120 \\
\hline
\end{tabular}

$P$ value: 0.0001

Among the 11 central causes of vertigo diagnosed by E.N.G., a M.R.I. of brain showed 3 patients $(27.27 \%$ ) had cerebellar lesion, $1(9.09 \%)$ had brainstem lesion and in 7 $(63.63 \%)$ no structural pathology was seen. The $\mathrm{p}$ value for this comparison was extremely stastically significant (Table $5)$.

Table 5: Diagnostic sensitivity of E.N.G. vs. MRI for central pathology

\begin{tabular}{lcc}
\hline Disease & ENG & MRI \\
\hline Central pathology detected & 11 & 4 \\
Central pathology not detected & 0 & 7 \\
\hline
\end{tabular}

P value: 0.0039

\section{Discussion:}

In North America, the first individual to publish a paper about E.N.G. was a neurologist, Dr. Leon Meyers ${ }^{2}$ (1929) from Los Angeles General Hospital. Mowrer ${ }^{3}$ (1935) was the first otolaryngologist to employ E.N.G. at Yale and demonstrate that the corneo-retinal potential was the source of the electrical recordings. Soon, E.N.G. was picked up by otolaryngologist Perlman (1939) ${ }^{4}$ at the university of Chicago. Mehra ${ }^{5}$ (1964) used to record horizontal nystagmus electrically by placing three small electrodes on patient's forehead using A.C. preamplifier. Guedry and Turnipseed ${ }^{6}$ (1968) used electromechanical shape computer and electronic summation device to analyze their E.N.G. as it helped to get quick and reliable analysis and avoid artifacts.

The advantages of electronystagmography as mentioned by Jongkees et $\mathrm{al}^{7}$ (1962) and Hooper et $\mathrm{al}^{8}$ (1971) are:

1. It can demonstrate nystagmus with the eyelids closed and thus avoids optic fixation which may abolish spontaneous nystagmus.

2. It allows quantitative analysis of the velocity, amplitude, frequency and duration of spontaneous and induced nystagmus, and provides a permanent record of these details.

3. E.N.G. provides a curve, which can serve as an objective basis for discussion, which is more profitable if a concrete document is available, rather than with a verbal description of visual impressions. Furthermore, when curves of patients are filed a good insight into the course of the disease can be obtained.

4. It helps in the differentiation of nystagmus from pendular and atactical eye movements that may occur in cerebral arteriosclerosis and cerebellar lesions.

5. Many strange eye movements in patients, who are sent with the diagnosis of nystagmus, prove to be no nystagmus at all during E.N.G.

The disadvantages of electronystagmography as mentioned by Jongkees et $\mathrm{al}^{7}$ (1962) and Hooper et al ${ }^{8}$ (1971) are:

1. Rotary nystagmus of benign paroxysmal positional vertigo cannot be recorded.

2. On posture testing of normal subjects with the eyes closed, $31 \%$ of subjects show some nystagmus using E.N.G. with the eyes closed. 
During the non-caloric tests in E.N.G., 111 patients (80.43\%) among the pathological group had their nystagmus enhanced by eye closure which is indicative of a peripheral lesion, 11 (7.97\%) had one or more of the criteria for a central lesion present. 7 (5.07\%) patients had spontaneous nystagmus out of whom 4 belonged to central group while 3 belonged to peripheral group. Thus, presence of spontaneous nystagmus had no localizing value. Among the control group 48 (96\%) had normal response and 2 (4\%) had spontaneous nystagmus of no localizing value. Stoddart et al ${ }^{9}(2000)$ stated that central vestibular system lesions will be commonly identified by an appropriate abnormality in at least one of the following tests: gaze test, saccades, smooth pursuit tracking and positional testing. Hood ${ }^{10}$ (1968) had stated that when the lesion is at labyrinthine level or peripheral to vestibular nuclei the nystagmus gets enhanced by eye closure if present or made manifest if not. When the lesion is above the level of vestibular nuclei the nystagmus does not get enhanced by eye closure.

During caloric tests in E.N.G., 12 (8.96\%) patients among the pathological group had normal response, 111 (80.43\%) had peripheral lesion, 11 patients $(7.97 \%)$ had central lesion and 4 patients $(2.89 \%)$ had non-localizing lesions. Among the control group $48(96 \%)$ had normal response and $2(4 \%)$ had peripheral lesion. The $\mathrm{p}$ values for these observations were statistically significant.

Conventional bithermal caloric test identified a nystagmus in 18 out of $138(13.04 \%)$ patients while E.N.G. assisted bithermal caloric test identified a nystagmus in 126 out of $138(91.30 \%)$ patients. Thus in our study the sensitivity of identifying a nystagmus increased 7 times when comparing conventional bithermal caloric test to E.N.G. assisted caloric test. This finding was extremely statistically significant ( $p$ $=0.0001$ ). Jongkees and Philipszoon ${ }^{1}$ (1964) concluded that nystagmus can be observed 4 times more frequently by electronystagmography than without. Jongkees, Maas and Philipszoon ${ }^{7}$ (1962) found, with the aid of E.N.G. 230 cases showing spontaneous and positional nystagmus in 341 patients complaining of vertigo, while without E.N.G. only in 52 of these patients was a nystagmus found. Spector ${ }^{11}$ (1971) found the incidence of nystagmus to increase 10 times with E.N.G. than without it. Directional preponderance might be of a central origin as well as of a peripheral origin thus diminishing its diagnostic value. The younger the patient, the more pronounced the association between the directional preponderance and central disease. (Eviatar and Wassertheil ${ }^{12}, 1971$ ).

Among the 11 central causes of vertigo diagnosed by E.N.G.,
4 cases $(36.37 \%)$ were also diagnosed by MRI but in 7 cases $(63.63 \%)$ no structural pathology was seen in MRI. The $\mathrm{p}$ value for this comparison was extremely stastically significant (0.0039). Stoddart et al ${ }^{9}$ (2000) reported 23 patients undergoing MRI after having demonstrated abnormal E.N.G. recording of central lesion. Only seven (30\%) had pathological MRI findings. Similarly, Kinney et $\mathrm{al}^{13}$ (1998) calculated the diagnostic sensitivity of MRI to be only $30 \%$, using E.N.G. as the gold standard. The hypothesis given for this disparity was either that the $70 \%$ of the cases with normal MRI had changes which were functional rather than structural, or that the structural changes were outside the resolution capacities of the MRI. Stoddart et al ${ }^{9}$ (2000) concluded that E.N.G. and MRI complement each other as clinical investigations, rather than provide the same information. E.N.G. is able to detect abnormalities of the function in the central vestibular system, thus has a value in the diagnosis of structural abnormalities that have a functional consequence, whereas MRI has value in the detection of structural lesion.

Our study results can be aptly summarized by the words of C.W. Hart ${ }^{14}$ (1985): "E.N.G. testing is a relatively noninvasive, clinically proven, cost effective technique that is currently for a variety of reasons underutilized".

\section{Conclusions:}

1. Electronystagmography has 7 times more sensitivity to elicit nystagmus when compared to Fitzgerald Hallpike bithermal caloric test.

2. Electronystagmography can pick up central causes for vertigo amongst cases clinically diagnosed as peripheral vertigo.

3. Electronystagmography has a better sensitivity to diagnose a central cause for vertigo when compared to Magnetic Resonance Imaging of brain.

\section{References:}

1. Jongkees L and Philipszoon AJ. The posture test. Acta Otolaryngol. 1964; 189: 20-21.

2. Meyers L. Electronystagmography. A graphic study of the action currents in nystagmus. Arch Neurol Psych. 1929; 21: 901-918. http://dx.doi.org/10.1001/ archneurpsyc. 1929.02210220172009

3. Mowrer $\mathrm{OH}$. The corneo retinal potential difference as the basis of the galvanometric method of recording eye movements. Am J Physiol. 1935-36; 114: 423-428. 
Original Article | Sharma V, et al. Conventional vestibular function tests

4. Perlman HB. Nystagmus: some observation based on an electric method. Laryngoscope. 1939; 49: 217-228. http://dx.doi.org/10.1288/00005537-193903000-00005

5. Mehra YN. Electronystagmography: A study of caloric test in normal subjects. J Laryngol Otol. 1964; 78: 520-529.

http://dx.doi.org/10.1017/S0022215100062332

6. Guedry FE, Turnipseed GT. Two devices for analysis of nystagmus. Ann Otol. 1968; 77: 1071-1085.

7. Jongkees L, Mass J, Philipszoon A. Clinical nystagmography. Detailed study of electronystagmography in 314 patients with vertigo. Pract otorhinolaryng. 1962; 24: 65-93.

8. Hooper RE, Worgan D, Clinical electronystagmography. J Laryngol Otol. 1971; 85: 23-33. http://dx.doi.org/10.1017/S0022215100073102

9. Stoddart RL, Baguley DM, Beynon GJ, Chang P and Moffat DA. Magnetic resonance imaging results in patients with central electronystagmography findings. Clin Otolaryngol. 2000; 25: 293-297. http://dx.doi.org/10.1046/j.1365-2273.2000.00369.x
10. Hood JD. Electronystagmography. J Laryngol Otol. 1968; 82: 167-183.

http://dx.doi.org/10.1017/S0022215100068651

11. Spector M. Horizontal nystagmus in routine subjects on electro-nystagmography. J Laryngol Otol. 1971; 85: 1039-1045.

http://dx.doi.org/10.1017/S0022215100074442

12. Eviatar A, Wassertheil S. The clinical significance of directional preponderance concluded by electronystagmography. J Laryngol Otol. 1971; 85: 355-367.

http://dx.doi.org/10.1017/S0022215100073539

13. Kinney WC, Wallace RC, Ross JS, Kinney SE, Hamid MA. Retrospective blinded review of magnetic resonance imaging in patients with central electronystagmography findings. Am J Otol. 1998; 19: 341-344.

14. Hart CW. Electronystagmography and vestibulogy: past, present and future. Am J Otol. 1985; 6: 512-513. 